\title{
Metacognitive Mathematics Tutor: Mathematics Tutoring System with Metacognitive Strategies
}

\author{
Asad Raza \\ Isra University \\ Hyderabad, Pakistan
}

\author{
Hameedullah Kazi \\ Isra University \\ Hyderabad, Pakistan
}

\author{
Muhammad Ali Nizamani \\ Isra University \\ Hyderabad, Pakistan
}

\begin{abstract}
The key aim of this research was to investigate the metacognitive mathematics tutor impact on students learning and metacognition. Student needs special learning strategies to experience better learning in mathematics. Metacognitive Mathematics tutor is an intelligent tutoring system which supports three metacognitive learning strategies self explanation, self questioning and self monitoring. Metacognition is higher order thinking. Metacognitive strategies are learning strategies which supports student learning. Students can improve their learning through metacognition skills. Total 70 students were involved in evaluation of Metacognitive mathematics tutor, 35 were sixth and 35 were seventh grade students. Pretest and Posttest experimental design was used for evaluation. Students used mathematics practice sheet in pretest then in posttest they had used Metacognitive mathematics tutor. A quiz was conducted to measure learning while Jr. MAI version B was also given to assess metacognitive skills. Results show that students learning have increased and also their metacognition after using the metacognitive mathematics tutor. Statistically significant difference in results between pretest and posttest (Man-Whitney, $p<0.05$ ) have been observed.
\end{abstract}

\section{General Terms}

Intelligent tutoring systems, learning

\section{Keywords}

Intelligent tutoring system, Metacognition, Learning, Self explanation, Self questioning, Self monitoring

\section{INTRODUCTION}

Usually students face struggle in learning specifically in mathematics. Students need effective instructions and strategies for learning mathematics. Students find helpful to use learning strategies for improving their learning [1].

Role of Metacognition in learning is widely researched and it has been revealed that metacognition improves the learning performance [2-4]. An Intelligent tutoring system for mathematics with metacognitive support can enhance the effectiveness of the tutoring system and improves student learning. Different work has been done on metacognition role in student learning for different domains like chemistry [5], HTML [6] SQL tutor [7], Science [8].

Most students game the system hints and how to make hint more effective so students can get benefit from system hint. Commonly students use hints in tutoring systems and showing hint as an example or instruction may be result in game of the system; students used hint to get help but the problem here is which form of hint student want from system. How to ask students what they got after finishing problem solving activity and how student could know about their learning behavior and problem solving activity from frequency of wrong or right question attempts to using hints.

The proposed solution by devising metacognitive strategies, designing and developing an intelligent tutoring system, metacognitive mathematics tutor to make intelligent tutoring system more effective. Some students did not understood entire problem while other students partially understood it but need just little help to solve the problem so there should be not sequence of hints but hint will show according to student need so here self questioning has been used to reduce game hint. Students while reading hints should self explain their understanding of each step which supports their learning. After finishing problem solution, students submit self explanation of their understanding and finally after that system would show a snapshot of overall activity which is self monitoring so that student can monitor their learning activities from using hints to generating self explanations.

The rest of paper organized as follows. Section 2 gives brief introduction of intelligent tutoring system, section 3 describe metacognition and three learning strategies, section 4 is about materials and method, section 5 presents results and discussion and finally section 6 is conclusion.

\section{INTELLIGENT TUTORING SYSTEM}

Intelligent tutoring system is educational software which provides intelligent feedback to students without intervention of human tutor. It is more advanced version of Computer Aided Instruction (CAI) [9]. Intelligent tutoring system first introduced by Brown [10] as more innovative term for intelligent computer aided instruction (ICAI). Intelligent tutoring systems involves investigation of design and develop learning strategies and learning systems for effective and better learning as good teachers do [11]. A number of intelligent tutoring systems have been developed for different subjects. Mathematics needs very effective strategies to learn.

Intelligent tutoring systems different from traditional computer based learning systems or computer aided instruction (CAI) because intelligent tutoring provides feedback and guidance to student about their learning performance without involving of any human tutor. Intelligent tutoring system has lot of advantages, their flexibility of time and place, student can learn at any time and location without any area limitation.

The effectiveness of intelligent tutoring system has been analyzed with traditional class rooms [12]. Researchers have developed intelligent tutoring systems for different subjects, andes [13], PHP [14], SQL [7] and computer programming [15]. Mathematics needs very effective strategies to learn. Intelligent tutoring systems for mathematics has been designed, Activemath [16], Wayang outpost [17] and Mathesis [18]. 


\section{METACOGNITION}

Process in mind like problem solving, remembering, comprehension, reasoning is called cognition [19-20]. Metacognition is cognition about cognition. Metacognition is defined as thinking about thinking or knowing about knowing and it is higher order thinking, knowledge and awareness of your cognition [21-23]. It has been discovered that metacognition improves learning performance so students which have higher metacognitive skills are better learners [23]. Mainly metacognition is divided into two main components, knowledge of cognition and regulation of cognition. Knowledge of cognition is awareness of own cognition. Knowledge of cognition is divided into three types, declarative knowledge, procedural knowledge and conditional knowledge. Regulation of cognition is defined as control your own cognition. Regulation of cognition is consists of three sub components Planning, monitoring and evaluation. Metacognitive learning strategies can help students to get better learning. Three metacognitive strategies self explanation, questioning and monitoring are included in metacognitive mathematics tutor to support students learning and metacognition.

\subsection{Self Explanation}

Self explanation is metacognitive learning strategy to explain oneself learning material in order to acquire better understanding and knowledge [24]. Self explanation is a reflective task of explaining oneself learning content in order to understand each and every line of content. Students use self explanation to explain themselves what they understood when they are reading text, reading a workout example of mathematics, step of problem instructed by teacher, human tutor or computer based tutor like intelligent tutoring system. Self explanation is strategy of thinking out loud. Students can generate right or wrong explanations about their understanding.

Self explanation can be defined with two processes inference generation and conceptual revision which is reflective in nature. Inference generation can be used to find learners who induce information from workout examples, text, instruction or explanation and through inference generation students will involve in struggling for new knowledge to explaining themselves. Self explanation also used in conceptual revision. When students read text or worked out example with their primary understanding, after reading example, student can identify flaws in his primary mental model with current understating which results in repaired mental model of understanding which do concept revision and transfer new knowledge [25].

According to cognitive load theory working memory is limited and problem solving, self explanation generation requires high cognitive load by monitoring their understanding, generating inference and represent information at same time [26]. Self explanation strategy needs scaffold support in learning to reduce cognitive load and encourage students to generate self explanation to improve their learning. Learners who were asked to generate explanations and were also provided feedback of their quality of self explanation like high quality explanations or low quality explanations, those students performed well in problem solving as compared to those who were only asked to explanation themselves without feedback [27].

Mostly researchers used self explanation to support better learning. Interactive learning environment [6] used two modes of self explanation to write understanding for HTML, SQL
Tutor [7] used self-explanation to explain worked out examples of SQL, English grammar tutor with self explanation support [28]. Geometry explanation tutor [29] used two modes of self explanation, one is dialogue based and other is menu based self explanation to investigate effects of learning in geometry. Self explanation prompts integrated with multiple graphical representations of fraction for more effective learning [30].

\subsection{Self Questioning}

Self questioning is metacognitive strategy used for monitoring reading comprehension and problem solving. It has been used for knowledge monitoring and knowledge acquisition and that questioning generation results in improved comprehension [31]. Self questioning has been practiced by asking questions to oneself for monitoring cognition so consequently it will regulate cognition. It has more advantage in teaching and learning. It involves learners to ask oneself particularly fruitful questions in the course of solving problem or performing any learning activity and trying to answer those questions themselves. Questions are learning tools that allow students to pay focus on a particular topic, performance or participation. Question and question generation force the students to think.

Self questioning used by many researchers to support learning Question bank [32], Reading comprehension [33] and problem solving in circuit theory course [34].

\subsection{Self Monitoring}

Self monitoring is metacognitive strategy involves observe, measure and record student behaviors and their own learning performances. It is student centered activity and promote independent learning. Self monitoring mainly provides three features. First is monitoring related to self-evaluation, secondly monitoring of which strategy used to enhance progress and finally monitoring of learning outcome to adjust learning strategies. All these features are used by students for self monitoring their learning progress and goal. Self monitoring is a step of self regulation, students can regulated their learning through self monitoring. Students actively used self monitoring during their learning improved their academic performance and problem solving skills. This strategy can be used as regulation of your cognition through observations and measuring your progress and it assists as a guide and get awareness of all learning performance without any teacher intervention. Students can change behavior and find their weakness to achieve their learning goals [35].

Self monitoring improve the awareness of students itself such as how well you are doing and student takes control of its own learning and through it students can evaluate itself without intervention of any teacher or tutor and student is responsible of its own progress. Self monitoring can increase self efficacy beliefs in students by taking control of its own learning process [36]. If any student is engaged in problem solving activity of mathematics with an intelligent tutoring system or any educational software, all student problems solving activity like number of correct attempts and incorrect attempts or how much he used hints or which hint he used during problem solving, all these activities are related to its learning progress. So if student observed its entire problem solving activity he can adjust its learning strategy or he can self evaluate itself learning progress. Teaching students to self monitoring their learning is very important and also important for students for all ages and for school, college to university level. 
Self monitoring is implemented by many researchers. TraVis is online distance learning communication tool integrated self monitoring which results positive feedback from students and teachers [37]. Students have improved their academic performance in English as foreign language using self monitoring in web based learning environment [38].

\subsection{Assessing metacognition}

Metacognition is internal process and assessing metacognition is critical process. Self-report questionnaire is a method to measure student metacognition. Jr. MAI (junior metacognitive awareness inventory) is self-report questionnaire used to measure metacognition of young students [39]. Authors have designed two versions of questionnaire version $\mathrm{A}$ and $\mathrm{B}$. Version A is used for 3 to 5 grade students which consists of 12 items and version B is used for 6 to 9 grade students which consists of 18 items. Researchers have used Jr. MAI in their research studies to assess metacognition. It has been used as offline measure to assess student metacognition [40]. Students learning and their metacognition relationship were studied in hypermedia environment though using a science website with linear and nonlinear structure, Jr. MAI used to assess student metacognition [41]. Relationship between science achievement, metacognition and epistemological beliefs of fourth and eighth grade students were explored, Jr. MAI used for metacognition assessment [42]

\section{MATERIALS AND METHOD 4.1 Participants}

There were total 70 students participated in study, 35 students were sixth grade and 35 seventh grade students.

\subsection{Mathematics Practice sheet}

Mathematics practice sheet consists of 10 worked out examples. It was used in pretest. There were two mathematics practice sheets one was for sixth grade students and second for seventh grade students. Sixth grade student mathematics practice sheet consists of fraction worked out examples and seventh grade students sheet was consists of proportion worked out examples. Mathematics practice sheet was given to students in their classes to practice problems.

\subsection{Learning assessment test}

Learning assessment test is a quiz paper consists of 8 questions in MCQs (Multiple Choice Questions) format. It was used to evaluate students learning in pretest and posttest. Scoring of student questions was 1 on correct answer and 0 on wrong answer. Learning assessment test was conducted from both grade students in pretest and posttest to evaluate students learning. It was conducted after finishing practice with mathematics practice sheet and Metacognitive mathematics tutor.

\subsection{Metacognitive mathematics tutor}

Metacognitive mathematics tutor is an intelligent tutoring system which supports metacognitive strategies. Self questioning is used to reduce game hint, student is selecting option from dropdown to ask themselves "why i used hint?", first option is "I did not know how to solve problem" and second is "I need just a little hint" Figure 5. System will show worked out example hint when student have selected first option and self explanation is integrated with each step so that student can do self explanation after reading each step Figure 3. In second option system will show a brief hint related to problem and then open prompt is also given to submit student self explanation Figure 4. Give up option is also given if student could not able to give correct answer after five wrong attempts, after give up system will show problem solution with self explanation integrated with each step. After completing problem student will submit their self explanation what he understood and acquires knowledge Figure. 6. Frequency of wrong attempts and snapshot of problem solving activity will be shown to students after completing problem which is used to self monitoring of problem solving activity after that student will directed to next problem Figure 7. Flow chart of learning activity in Metacognitive mathematics tutor is given in Figure 2.

\subsection{Junior Metacognitive Awareness Inventory version B (Jr. MAI)}

Jr. MAI is self-report questionnaire to assess metacognition of young population. It consists of two versions. Version A is designed for 3 to 5 grade students which consist of 12 items and version B is for 6 to 9 grade students and consists of 18 items. Participants of evaluation were sixth and seventh grade students so Jr. MAI version B was selected to assess student metacognition. Jr. MAI B is based on 5 point like scale $(1=$ Never, $2=$ Seldom, 3 = Sometime 4 = Often, $5=$ Always $)$.

\subsection{Pretest and Posttest experiment}

Pretest and Posttest experiment design was used for evaluation of metacognitive mathematics tutor. Fraction chapter was selected for sixth while proportion chapter was selected for seventh grade students.

Pretest was conducted in class. In pretest, mathematics practice sheet was given to sixth and seventh grade students in their classes. Practice sheet consists of 10 worked out examples. Students were instructed that they have to practice using this practice sheet for one period. They were given 3 days total 3 periods, each period duration is 45 minutes. Students were also instructed that test would be conducted to evaluate their learning after completing practice. Learning assessment test which is mathematics Quiz consist of 8 questions with MCQ's options was conducted after three days to evaluate their learning which is collected as pretest score. Jr. MAI B was also attached with test so that students after completing test they respond to questionnaire to assess their metacognitive skills.

Posttest was conducted in computer lab. Before posttest, one period was conducted for teaching students about the computer based tutoring and these three metacognitive learning strategies. In Posttest same group of students practice with same chapter but different problems with Metacognitive mathematics tutor in computer lab. Students were instructed that they have to practice problems with metacognitive mathematics tutor for one period of 45 minutes. Three days was given to students for practicing problems after that assessment was conducted using learning assessment test along with Jr. MAI B to evaluate their learning and assess their metacognition skills.

\section{RESULTS AND DISCUSSION}

The aim of research study was to design, develop and evaluate metacognitive mathematics tutor which is an intelligent tutoring system and devising metacognitive strategies self explanation, questioning and monitoring in metacognitive mathematics tutor to support students learning in mathematics domain, consequences of intelligent tutoring system with metacognitive learning strategies has shown an increase in learning and metacognition. The system was evaluated using learning assessment test and Jr. MAI version B. 
Learning assessment test and Jr. MAI version B results were collected and calculated to evaluate metacognitive mathematics tutor. Pretest and Posttest results of learning and Jr. MAI B are presented in Table 1.

Table 1. Pretest and posttest of learning assessment test and Jr. MAI B

\begin{tabular}{|c|c|c|}
\hline Measure & Pretest & Posttest \\
\hline & $\operatorname{Mean}\left(\mathrm{SD}^{*}\right)$ & $\operatorname{Mean}\left(\mathrm{SD}^{*}\right)$ \\
\hline $\begin{array}{l}\text { Learning } \\
(\mathrm{N}=70)\end{array}$ & $2.86(1.05)$ & $4.20(1.29)$ \\
\hline $\begin{array}{c}\text { Jr. MAI B }(\mathrm{N}= \\
70)\end{array}$ & $52.54(6.10)$ & $61.20(6.18)$ \\
\hline
\end{tabular}

*Standard Deviation

Table 2 shows the learning outcome and Jr. MAI B results of both sixth and seventh grade students.

Table 2. Pretest and Posttest Learning Assessment Test and Jr. MAI B results of $6^{\text {th }}$ and $7^{\text {th }}$ class

\begin{tabular}{|c|c|c|c|c|}
\hline \multirow{2}{*}{ Class } & \multicolumn{2}{|c|}{ Learning } & \multicolumn{2}{c|}{ Jr. MAI B } \\
\hline \multirow{2}{*}{} & Pretest & Posttest & Pretest & Posttest \\
\cline { 2 - 5 } & Mean(SD) & Mean(SD) & Mean(SD) & Mean(SD) \\
\hline $\begin{array}{c}6^{\text {th }} \\
(\mathrm{N}=35)\end{array}$ & $2.80(1.08)$ & $4.34(1.28)$ & $52.34(6.83)$ & $62.23(7.77)$ \\
\hline $\begin{array}{c}7^{\text {th }} \\
(\mathrm{N}=35)\end{array}$ & $2.83(1.06)$ & $4.08(1.31)$ & $52.13(5.58)$ & $59.63(6.20)$ \\
\hline
\end{tabular}

Learning Assessment test consist of 8 questions. These questions result in percentage from pretest to post is presented in Figure 1.

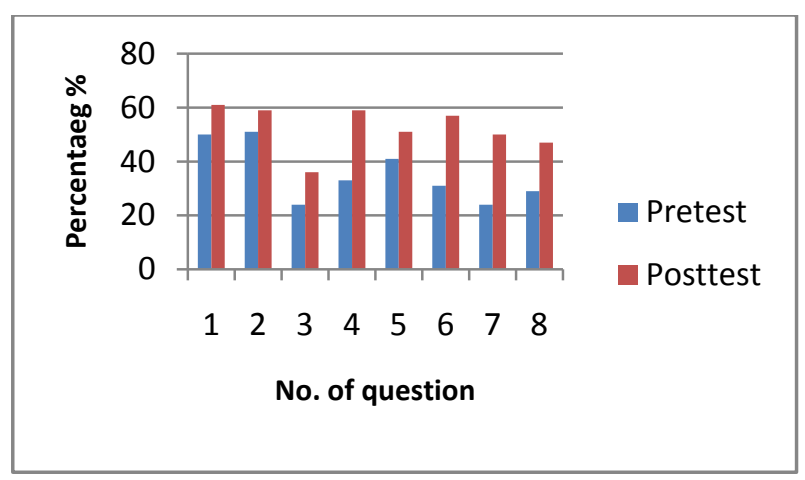

Fig 1: Pretest Posttest questions results of learning assessment test

The difference between pretest and posttest results of learning assessment has been found statistically significant (MannWhitney U, p <0.05). Further exploring more detailed data of sixth and seventh grade students, both grade students learning mean score has increased from pretest to posttest, there is difference in mean of both grade students, however difference is small but from that it can be conclude that sixth grade students learning is more than seventh grade students, overall students got improvement from pretest to posttest as shown in Table 1. Analyzing Percentage score of all eight MCQ's of learning assessment test in pretest and posttest there is rise from pretest to posttest percentage score as shows in Figure 1.

Jr. MAI is self-report questionnaire to assess metacognition of young population. Students had practice problems with metacognitive mathematics tutor using metacognitive learning strategies after using these metacognitive learning strategies, metacognitive skills of students have been improved. Table 1 results shows that there is progress from pretest to posttest score of Jr. MAI B with statistically significant difference (Mann-Whitney U, p<0.05). Table 2 shows results of both classes in more detail, both grade students metacognition has increased from pretest to posttest while sixth grade metacognition score is more than seventh grade score. Result finding explored that there is difference has found between sixth and seventh grade learning score also there is change between metacognition of both grade students.

Research study results explored that metacognitive strategies have benefited students learning and their metacognitive skills, so these findings suggested that students and teachers should use metacognitive learning strategies as part of their learning to achieve better and effective learning.

Self questioning strategy is integrated with hints as predefined prompts Figure 5 and system is saving entire activity of students from using hints to self explanations and their number of attempts and students just need monitoring their learning activity Figure 7. Open response self explanation prompt has been used for writing explanations after finishing problem and in hints Figure 3-4 and Figure 6. Students have to self explain in their own words learning material to develop deep learning, during conducting evaluation study and observing students open response self explanations, students did not input better response to open self explanations. Open response self explanation need students to typing their self explanations, much of students could not write enough self explanation due to less interaction to tutoring systems and weak typing skills also writing self explanations need more cognitive ability, so response to open self explanation was not exciting as expected, however students got better learning and have liked interaction with metacognitive mathematics tutor.

\section{CONCLUSION}

The objectives of this work was to devise metacognitive strategies and evaluation of metacognitive mathematics tutor which is an intelligent tutoring system for support students learning in mathematics of sixth and seventh grade students and their metacognitive skills. Pretest and posttest experiment design had been used to investigate students learning and metacognition. Results show that students have improved their learning after using metacognitive mathematics tutor and also using of these metacognitive strategies students improved their metacognitive skills. There is statistically significance difference in learning while metacognition results also showed statistically significant difference.

Self explanations are open statements submitted by students. These self explanations mostly judged by expert to classify quality of explanations like low quality self explanation or high quality self explanation. These self explanations can be evaluated by natural language processing model for classification of quality of self explanations and discovering relationship between students learning and quality of self 
explanations. Self explanation using menu based prompt could be more effective than open response self explanation, this area can be investigated which one is more effective for learning. Students self explanation of their understanding after completing problem solving activity can be more interactive and here could get more involvement of students in self explanation if there is dialog based self explanation scenario or spoken based self explanation or chatbot. Scope of this research work was narrow to school based education; this work can be further enhanced to tertiary education based mathematics to investigate students learning and metacognitive skills using intelligent tutoring system. Selfevaluation and self-reinforcement further two metacognitive strategies can be implemented with these three metacognitive strategies for developing an intelligent self management learning tool for supporting students independent learning. Self monitoring which is storing in database it can be used more for reflection as it can be saved as history so that students again self monitoring their historic progress of their activities and self monitoring snapshot can be sent to teachers and parents so that they could also know about theirs child performance.

\section{ACKNOWLEDGMENTS}

Authors are really thankful to school management which supported to take evaluation study and absolutely students who had participated in evaluation study.

\section{REFERENCES}

[1] D'ambrosio, B., Johnson, H., \& Hobbs, L. (1995). Strategies for increasing achievement in mathematics. Educating everybody's children: Diverse teaching strategies for diverse learners: What research and practice say about improving achievement. Alexandria, VA: Association for Supervision and Curriculum Development.

[2] Garofalo, J., \& Lester Jr, F. K. (1985). Metacognition, cognitive monitoring, and mathematical performance. Journal for research in mathematics education, 163-176.

[3] SAHIN, S. M., \& Kendir, F. (2013). The effect of using metacognitive strategies for solving geometry problems on students' achievement and attitude. Educational Research and Reviews, 8(19), 1777.

[4] Van der Stel, M., Veenman, M. V., Deelen, K., \& Haenen, J. (2010). The increasing role of metacognitive skills in math: a cross-sectional study from a developmental perspective. $Z D M, 42(2), 219-229$.

[5] Hollingworth, R. W., \& McLoughlin, C. (2001). Developing Science Students' Metacognitive Problem Solving Skills Online. Australian Journal of Educational Technology, 17(1), 50-63.

[6] Kwon, K., Kumalasari, C. D., \& Howland, J. L. (2011). Self-explanation prompts on problem-solving performance in an interactive learning environment. Journal of Interactive Online Learning, 10(2), 96-112.

[7] Najar, A. S., \& Mitrovic, A. (2013). Examples and tutored problems: How can self-explanation make a difference to learning?. In International Conference on Artificial Intelligence in Education (pp. 339-348). Springer Berlin Heidelberg.
[8] Leelawong, K., \& Biswas, G. (2008). Designing learning by teaching agents: The Betty's Brain system. International Journal of Artificial Intelligence in Education, 18(3), 181-208.

[9] Freedman, R., Ali, S. S., \& McRoy, S. (2000). Links: what is an intelligent tutoring system?. intelligence, 11(3), 1516.

[10] Sleeman, D., \& Brown, J. S. (1982). Intelligent tutoring systems.

[11] Conati, C. (2009). Intelligent Tutoring Systems: New Challenges and directions. In IJCAI (Vol. 9, pp. 2-7).

[12] Steenbergen-Hu, S., \& Cooper, H. (2014). A metaanalysis of the effectiveness of intelligent tutoring systems on college students' academic learning. Journal of Educational Psychology, 106(2), 331-347.

[13] Vanlehn, K., Lynch, C., Schulze, K., Shapiro, J. A., Shelby, R., Taylor, L., \& Wintersgill, M. (2005). The Andes physics tutoring system: Lessons learned. International Journal of Artificial Intelligence in Education, 15(3), 147-204.

[14] Weragama, D., \& Reye, J. (2013, July). The PHP intelligent tutoring system. In International Conference on Artificial Intelligence in Education (pp. 583-586). Springer Berlin Heidelberg.

[15] Butz, C. J., Hua, S., \& Maguire, R. B. (2006). A webbased bayesian intelligent tutoring system for computer programming. Web Intelligence and Agent Systems: An International Journal, 4(1), 77-97.

[16] Melis, E., \& Siekmann, J. (2004). Activemath: An intelligent tutoring system for mathematics. In International Conference on Artificial Intelligence and Soft Computing (pp. 91-101). Springer Berlin Heidelberg.

[17] Arroyo, I., Beal, C., Murray, T., Walles, R., \& Woolf, B. P. (2004). Web-based intelligent multimedia tutoring for high stakes achievement tests. In International Conference on Intelligent Tutoring Systems (pp. 468477). Springer Berlin Heidelberg.

[18] Sklavakis, D., \& Refanidis, I. (2013). MATHESIS: An Intelligent Web-Based Algebra Tutoring School. International Journal of Artificial Intelligence in Education, 22(4), 191-218.

[19] Cognition (2016). Wikipedia. Available: http://en.wikipedia.org/wiki/Cognition

[20] Neisser, U. (2014). Cognitive psychology: Classic edition. Psychology Press

[21] Metacognition (2016). Wikipedia. Available: http://en.wikipedia.org/wiki/Metacognition

[22] Flavell JH.(1979). Metacognition and cognitive monitoring: A new area of cognitive-developmental inquiry. American psychologist, 34(10), 906.

[23] Metcalfe, J. E., \& Shimamura, A. P. (1994). Metacognition: Knowing about knowing. The MIT Press.

[24] Chi, M. T., De Leeuw, N., Chiu, M. H., \& LaVancher, C. (1994). Eliciting self-explanations improves understanding. Cognitive science, 18(3), 439-477. 
[25] Chi, M. T. (2000). Self-explaining expository texts: The dual processes of generating inferences and repairing mental models. Advances in instructional psychology, 5 , 161-238.

[26] Sweller, J. (1988). Cognitive load during problem solving: Effects on learning. Cognitive science, 12(2), 257-285.

[27] Cheshire, A., Ball, L. J., \& Lewis, C. N. (2005). Selfexplanation, feedback and the development of analogical reasoning skills: Microgenetic evidence for a metacognitive processing account. In Proceedings of the Twenty-Second Annual Conference of the Cognitive Science Society, ed. BG Bara, L. Barsalou \& M. Bucciarelli (pp. 435-41).

[28] Wylie, R., Koedinger, K. R., \& Mitamura, T. (2009). Is self-explanation always better? The effects of adding self-explanation prompts to an English grammar tutor. In Proceedings of the 31st annual conference of the Cognitive Science Society (pp. 1300-1305).

[29] Aleven, V., Ogan, A., Popescu, O., Torrey, C., \& Koedinger, K. (2004). Evaluating the effectiveness of a tutorial dialogue system for self-explanation. In International Conference on Intelligent Tutoring Systems (pp. 443-454). Springer Berlin Heidelberg.

[30] Rau, M. A., Aleven, V., \& Rummel, N. (2009). Intelligent Tutoring Systems with Multiple Representations and Self-Explanation Prompts Support Learning of Fractions. In AIED (pp. 441-448).

[31] Wong, B. Y. (1985). Self-questioning instructional research: A review. Review of Educational Research, 55(2), 227-268.

[32] Draaijer, S., \& Boter, J.(2005). Questionbank: Computer Supported Self-Questioning. In Proceedings Of The 9th computer assisted assessment (Caa) Conference, Loughborough University, Loughborough.

[33] Mostow, J., \& Chen, W. (2009, July). Generating Instruction Automatically for the Reading Strategy of Self-Questioning. In AIED (pp. 465-472).
[34] Pate, M. L., \& Miller, G. (2011). Effects of Regulatory Self-Questioning on Secondary-Level Students' ProblemSolving Performance. Journal of Agricultural Education, 52(1), 72-84.

[35] Anastasia Kitsantas, Nada Dabbagh.( 2009). Selfmonitoring and Self-evaluation. In Learning To Learn With Integrated Learning Technologies (Ilt): A Practical Guide For Academic Success.(pp. 93-94).

[36] Schunk, D. H., \& Zimmerman, B. J. (Eds.). (1998). Selfregulated learning: From teaching to self-reflective practice. Guilford Press.

[37] May, M., George, S., \& Prévôt, P. (2011). TrAVis to enhance students' self-monitoring in online learning supported by computer-mediated communication tools. Computer Information Systems and Industrial Management Applications, 3, 623-634.

[38] Chang, M. (2010). Effects of self-monitoring on webbased language learner's performance and motivation. CALICO Journal, 27(2), 298-310.

[39] Sperling, R. A., Howard, B. C., Miller, L. A., \& Murphy, C. (2002). Measures of children's knowledge and regulation of cognition. Contemporary educational psychology, 27(1), 51-79.

[40] Sarac, S., \& Karakelle, S. (2012). On-line and Off-line Assessment of Metacognition. International Electronic Journal of Elementary Education, 4(2), 301.

[41] Schwartz, N. H., Andersen, C., Hong, N., Howard, B., \& McGee, S. (2004). The influence of metacognitive skills on learners' memory of information in a hypermedia environment. Journal of Educational Computing Research, 31(1), 77-93.

[42] Topçu, M. S., \& Y1lmaz-Tüzün, Ö. (2009). Elementary students' metacognition and epistemological beliefs considering science achievement, gender and socioeconomic status. Illköğretim Online, 8(3). 


\section{APPENDIX}

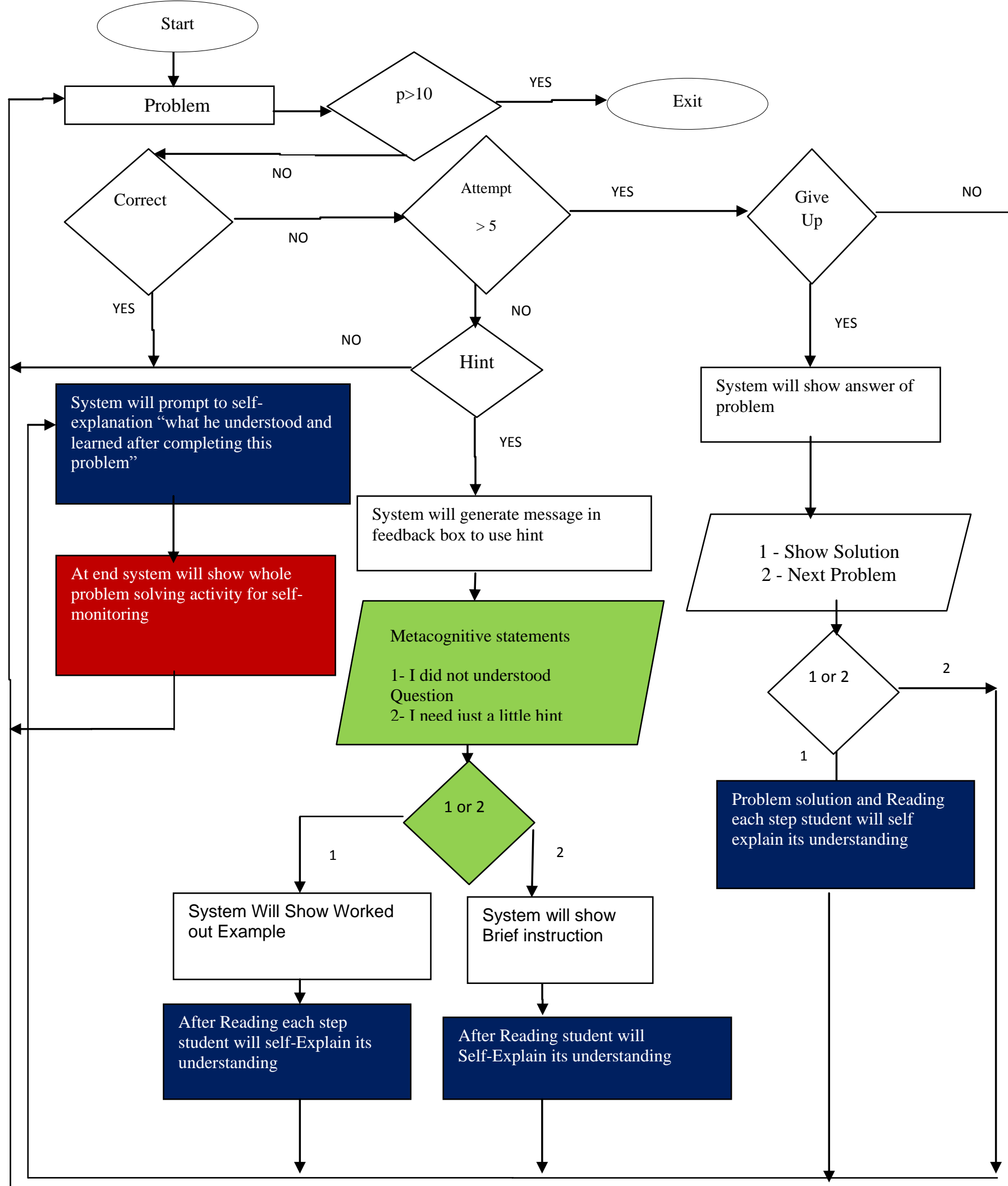

Fig 2: Flow chart of learning activity in Metacognitive Mathematics Tutor 
Instructions

\title{
- Read out hint and please self explain step and write in input field of step.
}

I did not know how to solve problem

\author{
What l understood? \\ (SelfExplain Each Step)
}

Example: vawad cycled a total of 4 kilometers by making 2 trips to work. After 7 trips to work, how many kilometers will Jawad have cycled in total?

\section{Solution:}

$4: 2$

make ratio of question

$x: 7$

$0: 4: 2=x: 7$

propotion of atio

$0,2 \times x=4 \times 7$

cross for mutipilication

$X=\frac{4 \pi^{7}}{2}$

multiply and divide

$=\frac{28}{2}$

divide 28 with 2

$x=14$

answeris 14

Back

Fig 3: Worked out example hint 
Instructions

Read out hint and please self explain step and write in input field of step.

Ineed just a little hint

Since Bill $E$ is directly proportional to Electricity usage $\mathrm{N}$

Then $E=\frac{k}{N}$, where $k$ is a constant.

$\operatorname{AsN}=2, E=1000$

What I Understood?

electricity increase bill also increases so it is direct proportion

Back

Fig 4: Brief hint 


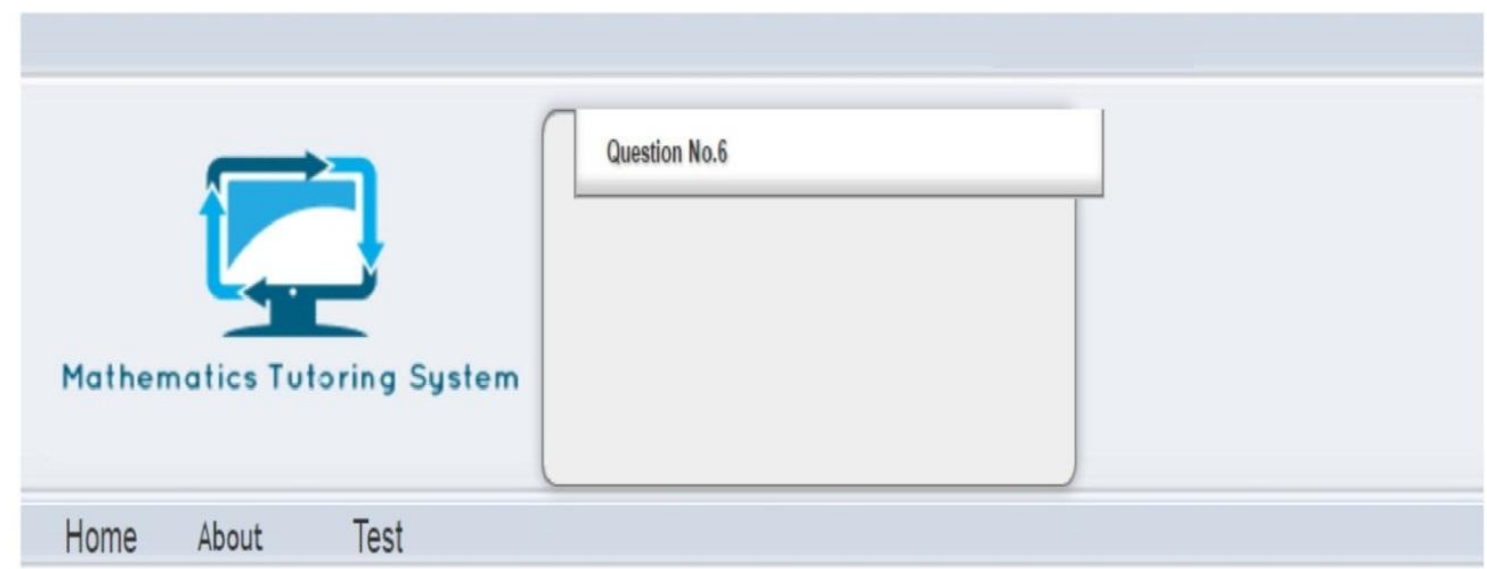

Why I used Hint?

\begin{tabular}{|l|}
\hline Please Select \\
\hline Please Select \\
I did not know how to solve problem \\
I need just a little hint
\end{tabular}

Fig 5: Metacognitive statements before hint

\begin{tabular}{l} 
Mathematics Tutoring System \\
Home About No.6 \\
\hline
\end{tabular}

Please write your Self Explanation.

What $i$ understood and learned after after finishing that problem solving activity?

leamed solving proportion problem |

submit

Fig 6: Self Explanation after finishing problem 


\section{Frequency Count}

Wrong Attempts : 2

Right Attempt: 1

Total Attempts : 3

Self Explanation After Problem Solving Activity

\section{solve fractions problem}

Note:Self Monitoring all your problem solving activity/Recommended)

\section{Next Questlon}

\section{Over all Problem Solving Activity}

User : I need just a little hint

You : Question Attempt

System : Wrong....

System:Please attempt again... You can use System Hint

User : I did not know how to solve problem

System Hint:

Example: Find $Z$ if $5: 10=2: X$

Solution:

$5: 10=2: x$

Please Self Explain this step 1 here

Or $\frac{5}{10}=\frac{2}{X}$

Please Self Explain this step 2 here

Or $\frac{5}{10} \times x=2$

Please Self Explain this step 3 here

Or $\frac{5}{10} \times x=2$

Please Self Explain this step 4 here

$X=\frac{20}{5}$

$X=4$

Please Self Explain this step 5 here

Please Self Explain this step 6 here

You : Question Attempt

System : Wrong....

System:Please attempt again... You can use System Hint

You: Question Attempt

System: Correct....

System : Next Question

Fig 7. Self monitoring 